\title{
ANÁLISE DO MERCADO DE MÍDIAS VISUAIS E SONORAS; UM ESTUDO DE CASO DA COMPETITIVIDADE ENTRE OS SERVIÇOS DE TELEVISÃO E STREAMING
}

Gustavo Henrique Bento da Silva (Instituto Federal de Educação, Ciência e Tecnologia do

Rio Grande do Norte) gustavohenrique.rn@ hotmail.com

Gustavo Leandro da Silva (Instituto Federal de Educação, Ciência e Tecnologia do Rio

Grande do Norte) gustavo.leandro.567@ gmail.com

Dinilson Ferreira da Silva Filho (Instituto Federal de Educação, Ciência e Tecnologia do Rio Grande do Norte) dinilson9@gmail.com

Isamara de Melo Dantas Bezerra (Instituto Federal de Educação, Ciência e Tecnologia do Rio Grande do Norte) isamaradantass@gmail.com

\section{Resumo}

O mercado competitivo como um todo vem alterando suas maneiras de ofertar seus produtos e serviços a população, se adequando as exigências de consumo do perfil dos clientes que buscam cada vez mais por serviços e produtos de qualidade e com preços acessíveis. O mercado consumidor de mídias visuais também está incluso nas novas mudanças de consumo, especificamente nos serviços de televisão a cabo e streaming. A TV a cabo vem enfrentando dificuldades em termos competitivos em relação ao serviço de streaming que vem recebendo cada vez mais adesão devido a suas vantagens atrativas em relação a TV a cabo. Visualizando tal cenário, no presente artigo foi-se analisado algumas das principais razões identificadas na pesquisa de mercado realizada que levam os consumidores a trocar de serviço, na qual se foi aplicado o diagrama de Ishikawa e a matriz GUT, buscando facilitar uma visualização mais clara das possíveis soluções para a problemática, ademais auxiliar as organizações do ramo a buscar novos meios de atender melhor a população com seus serviços.

Palavras-Chaves: Streaming, TV a cabo, Serviços, e Ferramentas da qualidade

\section{Introdução}

Com a crescente ascensão da tecnologia e suas ferramentas auxiliadoras, os serviços prestados adquirem uma nova perspectiva como referencial de qualidade e satisfação, uma vez que a população está mais exigente em relação aos bens e serviços que lhes são ofertados pelas empresas e organizações.

No mercado de consumo de mídias visuais e sonoras vivenciamos grandes mudanças, uma época de transição segundo Kischinhevsky, 2009. Tais mudanças vem acontecendo 
desde o rádio que foi substituído pela televisão, e agora a mesma se encontra praticamente na mesma situação de transformação.

A tradicional televisão também sofreu mudanças positivas em seu modo de ofertar entretenimento as casas da população de maneira geral, agora elas podem possuir o sistema de TV a cabo, uma tecnologia que busca ofertar canais diferenciados dos que são ofertados na TV aberta.

As pessoas ao desejarem adquirir tal serviço devem assinar planos, cujo mesmos disponibilizam pacotes com a quantidade de canais proporcional aos seus respectivos preços, também levando em consideração os canais que têm uma programação mais atraente aos olhos do público alvo.

Porém a TV a cabo ainda é um serviço que não possui grande abrangência a população devido a alguns fatores determinantes como preço, desinteresse pelos canais ofertados nos planos ditos "básicos" ou até mesmo por a falta de flexibilização de novos pacotes com o gosto do consumidor.

Os serviços de streaming são um novo mercado de grande potencial que viabiliza a flexibilidade de serviços ao gosto do cliente, fornecendo um fluxo praticamente infinito de mídias digitais, apostando na comodidade dos consumidores e capitalização das campanhas de criminalização do compartilhamento de fonogramas protegidos por direitos autorais.

Visualizando tal cenário, no qual a TV a cabo agora tem uma concorrência em potencial devido ao novo serviço de streaming no presente artigo se é estudado as problemáticas identificadas no sistema de TV a cabo e exposto meios de melhorar o atual serviço ofertado pelas empresas voltadas a esse sistema.

\section{TV por assinatura e sua queda}

O serviço por assinatura consiste no oferecimento de um serviço contínuo em troca de um pagamento. Esse pagamento é periódico, podendo ser feito de forma quinzenal, mensal e assim por diante. A televisão por assinatura surgiu na década de 80 segundo Betti (1999), devido a insatisfação dos telespectadores da TV aberta.

Ela consiste em oferecer uma programação maior e/ou mais diversificada em troca de certo valor, sendo pago continuamente, por exemplo, mensalmente. Nos anos 90 o serviço de TV por assinatura começou a se espalhar por diversos países, incluindo o Brasil, onde o 
serviço se popularizou de vez em 2003, após o fim da crise cambial se tornando uma indústria bastante lucrativa.

Figura 1- Evolução dos assinantes da TV a cabo.

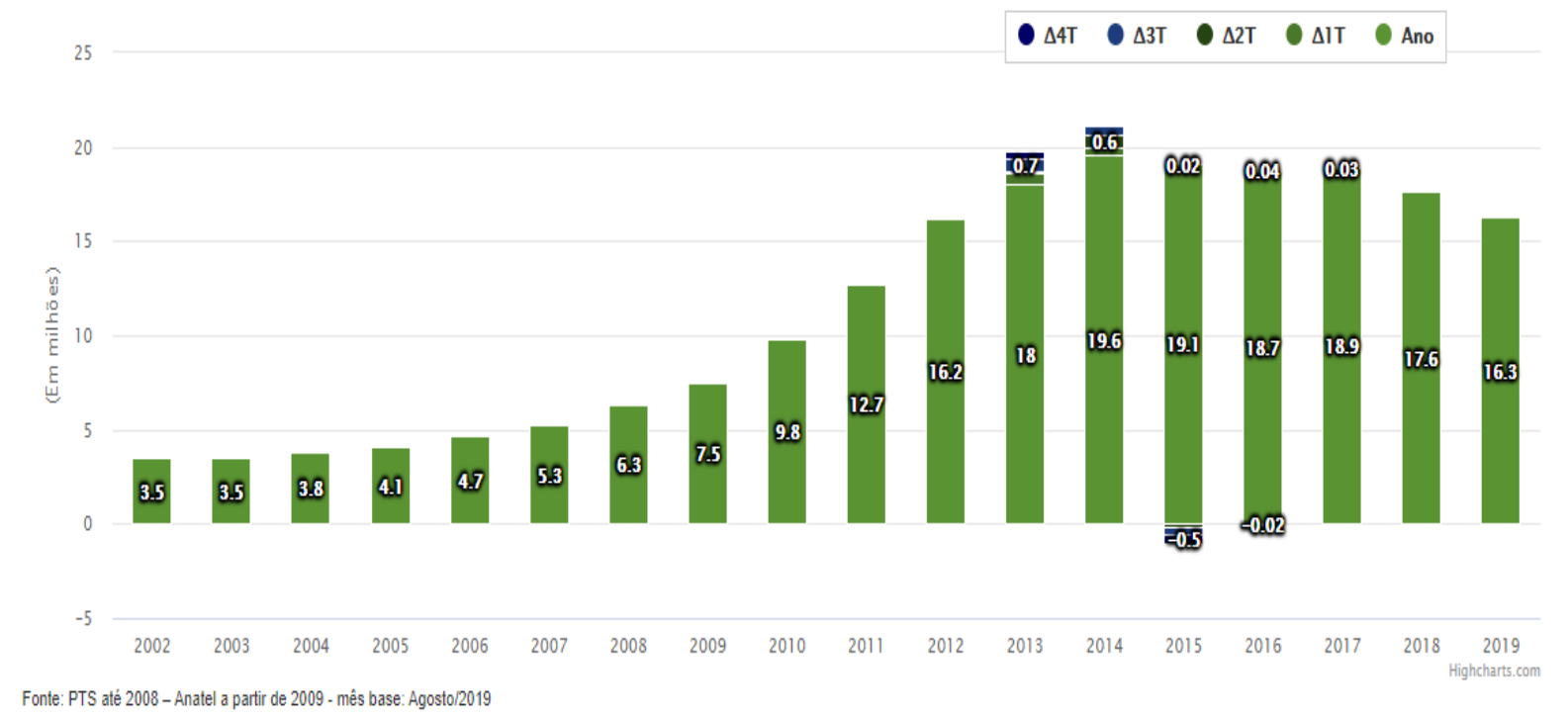

Fonte: ABTA (2019).

Na figura 1 é possível acompanhar o crescente número de usuários de TV por assinatura no Brasil desde o início dos anos 2000, mostrando a consolidação do serviço aqui no Brasil até o ano de 2015, onde ouve uma pequena queda nos números de usuários.

Segundo a Agência Nacional de Telecomunicações, ANATEL (2019) o serviço de televisão por assinatura sofreu uma queda de 549.833 assinantes no ano de 2018. Uma possível explicação para a queda no número de usuários é que serviço possa ter começado a ficar ultrapassado, devido ao seu encarecimento, gerando insatisfação nos clientes, além do surgimento de um grande concorrente, o serviço de streaming (vídeo).

O serviço de streaming (vídeo) é bastante similar ao serviço de TV por assinatura, ou seja, consiste em oferecer um serviço na qual se é cobrado uma tarifa após certo período, ele se deferência da TV por assinatura devido a sua maior flexibilização, onde se pode assistir filmes não só na TV, mas também em várias outras telas como em computadores, tabletes e smartphones. Além de ter uma maior flexibilidade, se comparada com a convencional TV por assinatura, os serviços de streaming possuem um preço bem mais competitivo e popular.

Com os serviços de streaming mais baratos e acessíveis, os clientes começaram a perder o interesse e começaram a migrar da TV por assinatura para o Streaming, ou que 
apenas cancelassem o serviço devido ao preço. Fazendo não só que o mercado de TV por assinatura estagnasse, mas também, entrasse em queda, aqui no Brasil. Na imagem abaixo mostra uma pesquisa (Realizada pela NEXO) mostrando a porcentagem de pessoas que possuem TV por assinatura em um determinado número de entrevistados.

Figura 2- Pesquisa de serviço.

\section{Acesso à TV por assinatura no brasil}

\section{$36 \%$ tem acesso}

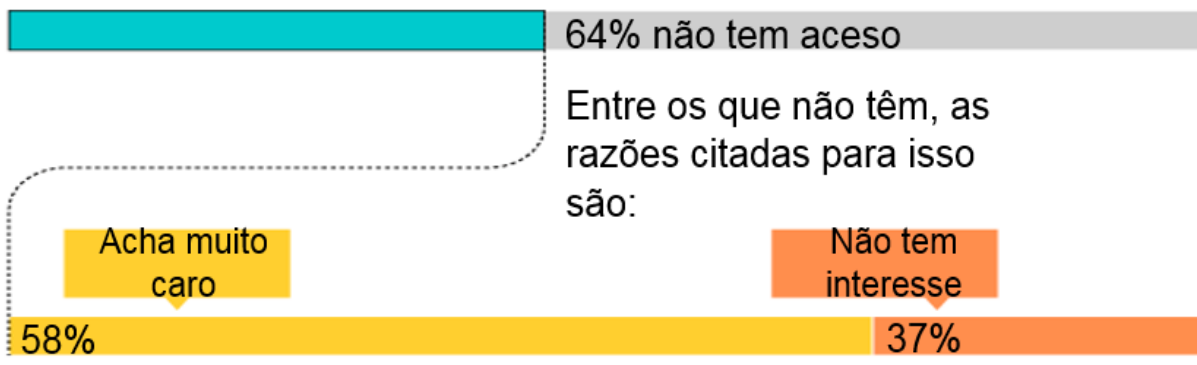

Fonte: Nexo jornal (2019)

Na figura 2 visualiza-se que entre $64 \%$ dos intrevistados não possuem acesso a TV por assinatura no Brasil, e isso se deve, em sua maioria, ao fato das pessoas acharem o serviço caro. Por isso que as empresas prestadoras de serviços de TV por assinatura devem buscar tecnologias auxiliadoras buscando inovação para conseguir atrair novamente o seu publico de volta, tentar conquistar novos clientes e fidelizar de vez os que já têm.

Com base nos dados coletados e apresentados no presente artigo sobre o que abrange os serviços de TV por assinatura, pode-se observar que desde 2018 esse tipo de serviço vem obtendo uma desistência nos contratos consideravelmente, sendo uma das principais causas a troca por serviços de streaming.

\subsection{Impacto social da TV nos lares}

Segundo Adorno \& Horkheimer (1998) televisão possui um enorme impacto nas nossas vidas, indo muito além de um simples eletrodoméstico, se tornando-se praticamente uma instituiçao de cunho social, um item extremamente participativo na indústria cultural.

Não que os outros meios de comunicação desaparecessem, mas foram reestruturados e reorganizados num sistema cujo coração era composto por válvulas eletrônicas e cuja fachada apelativa era uma tela de TV. A 
rádio perdeu a sua centralidade (...) os filmes foram adaptados para atender às audiências televisivas, com exceção da arte subsidiada pelo governo e dos espetáculos baseados em efeitos especiais das grandes telas. (CASTELLS, 2002, p. 432).

A TV, é, de longe, o meio de teleconunicação mais utilizado e popular do Brasil. Segundo o IBGE (O Instituto Brasileiro de Geografia e Estatística) de 69,3 milhões de domicílios particulares permanentes no Brasil - apenas 2,8\%, ou 1,9 milhão, não tinham televisão. A TV por assinatura também tem uma boa participação nos lares brasileiros.

a televisão (...) $26 \%$ dos lares brasileiros são atendidos por um serviço pago de televisão, $23 \%$ por antena parabólica e $72 \%$ possuem acesso à TV aberta. A posse de antena parabólica, presente nos lares dos entrevistados, apresenta características inversas às da TV paga. Enquanto a TV paga está presente nos grandes centros urbanos e é acessível os estratos mais ricos e escolarizados da população, a antena parabólica é mais comum no interior do país: sua posse é declarada por $49 \%$ dos entrevistados residentes em municípios com até 20 mil habitantes, contra $4 \%$ nos municípios com mais de 500 mil habitantes. (BRASIL, 2015).

$\mathrm{Na}$ Pesquisa Brasileira de Mídia 2015 "Hábitos de Consumo de Mídia pela População Brasileira", que foi feita pela Secretaria de Comunicação Social da Presidência da República, nota-se que boa parte dos brasileiros tem o hábito de assistir televisão diariamente.

De acordo Brasil (2015) 95\% dos entrevistados afirmaram ver TV, sendo que $73 \%$ têm o hábito de assistir diariamente. Em média, os brasileiros passam 4h31 por dia expostos ao televisor, de $2^{\mathrm{a}}$ a $6^{\mathrm{a}}$-feira, e $4 \mathrm{~h} 14$ nos finais de semana, números superiores aos encontrados na PBM 2014, que eram 3h29 e 3h32, respectivamente.

A TV é o meio de comunicação mais acessado pelos entrevistados, sendo mencionada pela quase totalidade da amostra. Pouco mais de três quartos dos entrevistados assistem TV todos os dias da semana. O acesso é mais frequente entre segunda e sexta-feira, e o tempo médio de acesso supera as três horas diárias. As emissoras da TV aberta são as mais assistidas, principalmente a Rede Globo (BRASIL, 2016, p. 33).

Atualmente, a TV é algo comum a quase todas as classes sociais, principalmente a TV aberta. A TV por assinatura também tem um grande público, esse público, porém, é composto por pessoas que possuem uma renda média/alta. Com o passar do tempo, as empresas prestadoras de serviços de assinatura não procuraram diversificar seu público 
(oferecer seus serviços para quem tem uma renda menor). Acabou ocorrendo o contrário, os pacotes de TV por assinatura ficaram mais caros com o tempo, fazendo com várias pessoas cancelassem a sua assinatura.

\section{Pirataria}

A pirataria é outro fator alarmante para as operadoras de TV por assinatura, o chamado "gatonet" segundo a ABTA gera uma perca de $\mathrm{R} \$ 8,7$ bilhões ao ramo, esse serviço ilegal está atuando de maneira firme e ágil e ganhando adesão e aceitação por parte da população por meio dos seus métodos e acessibilidade, que cobram valores bem abaixo da média das operadoras autorizadas a realizar a distribuição do sinal.

A forma com que realizam o atendimento de modo organizado e a falta de punição mais severa pela própria justiça não possuindo uma legislação definida pra esse tipo de crime facilita a propagação dessa prática.

Tal prática causa atordoamento na agilidade em como as operadoras do sistema de TVs a cabo iram fazer para manter seus clientes, pois além de se preocupar com os seus concorrentes do mesmo ramo, há as novas tecnologias que vem com grande potencial, e a pirataria acaba se tornando um fator crucial para essa baixa no número de assinantes.

\section{Fundamentação}

\subsection{Diagrama de Ishikawa}

O diagrama de Ishikawa basea-se em visualizar com mais clareza a problematica escolhida. Problema esse que deve ser colocado como a "cabeça do peixe", e suas causas elencadas onde seria as " espinhas do peixe", as subcausas são colocadas ao longo das linhas que seriam as "espinhas do peixe". 
Figura 3 - Diagrama de Ishikawa.

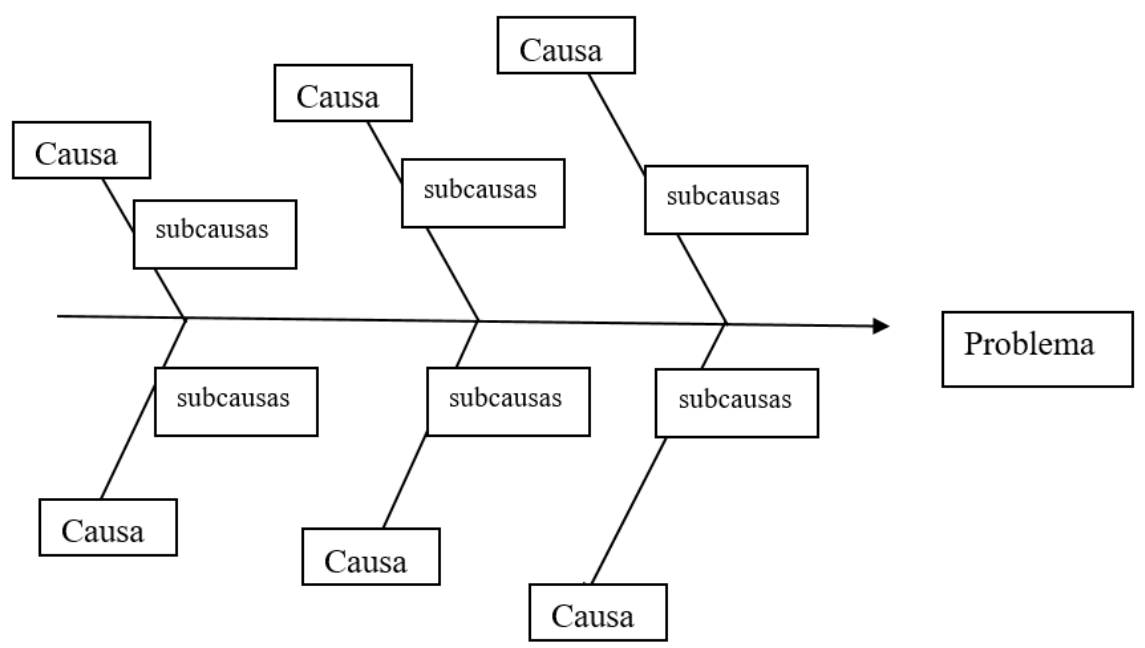

Fonte: Bezerra, Isamara \& Tinoco, Dellano (2019).

Este conceito de divisibilidade de um processo permite controlar sistematicamente cada um deles separadamente, podendo desta maneira conduzir a um controle mais eficaz sobre o processo todo. Controlando-se os processos menores é possível localizar mais facilmente o problema e agir mais profundamente sobre sua causa. (CAMPOS, 2004 apud SALGADO, L. 2008. p.9)

\subsection{Matriz GUT}

Segundo BEHR, Ariel. et al (2008) essa matriz é uma das alternativas de priorização das ações aplicadas a gestão. É sabido que muitas vezes a decisão é algo compartilhado, não dependendo unicamente de uma pessoa, por isso torna-se ainda mais válida esta abordagem quando realizada em grupo.

Tabela 1 - Matriz GUT

\begin{tabular}{|l|l|l|l|}
\hline nota & \multicolumn{1}{|c|}{ gravidade } & \multicolumn{1}{|c|}{ Urgência } & \multicolumn{1}{|c|}{ Tendência } \\
\hline $\mathbf{5}$ & $\begin{array}{l}\text { Extremamente } \\
\text { grave }\end{array}$ & $\begin{array}{l}\text { Extremamente } \\
\text { urgente }\end{array}$ & $\begin{array}{l}\text { Extremamente } \\
\text { tendencioso }\end{array}$ \\
\hline $\mathbf{4}$ & Muito grave & Muito urgente & Muito tendencioso \\
\hline $\mathbf{3}$ & Grave & Urgente & Tendencioso \\
\hline $\mathbf{2}$ & Pouco grave & Pouco urgente & Pouco tendencioso \\
\hline $\mathbf{1}$ & Sem gravidade & Sem urgência & Sem tendência \\
\hline
\end{tabular}

Fonte: Autores (2020) 
Consiste em analisar a gravidade, a urgência e a tendência dos problemas enfrentados, sendo: a. gravidade: o impacto do problema nas operações e pessoas envolvidas no processo; b. urgência: a brevidade necessária para a resolução do problema; c. tendência: apresentação de melhora ou piora do problema. Cada problema deve ser ponderado de 1 a 5 em cada critério.

\section{Metodologia}

A metodologia empregada é o estudo de caso, "O estudo de caso é caracterizado pelo estudo profundo e exaustivo de um ou de poucos objetos, de maneira a permitir conhecimento amplo e detalhado do mesmo". (GIL, 1994 apud ABBAS, K. 2001. p.19)

No presente estudo se foi analisado as problamaticas que se relacionavam a repentina baixa no número de assiantes do sistema de TV a cabo, e para descobrir e analisar as dificuldades identificadas se foi realizado uma pesquisa de mercado com intuito de levantar dados, visando embasar a real falha que o sistema possui.

A pesquisa foi realizada do tipo exploratoria, na qual os dados utilizados no presente artigo foram divulgados pela ABTA (Associação Brasieira de Televisão por Assinatura), revistas e artigos. $\mathrm{Na}$ qual os problemas identificados serão postos em algumas das ferramentas da qualidade para se poder ter uma visualização mais clara e assim poder tomar decisões com base em evidencias. Na qual se elencará as possiveis causas da perda de assinaturas no diagrama de Ishikawa e evidencia-las na matriz GUT.

\section{Pesquisa de mercado}

A aplicação da pesquisa de mercado consistiu em seis perguntas básicas, porém o suficiente para se constatar possíveis motivos que levaram as pessoas a repensar realizar a assinatura de pacotes de operadoras de TV a cabo, na pesquisa foram obtidas 63 respostas.

As perguntas realizadas no questionário implementado na pesquisa foram: 
- Você possui tv a cabo em casa?

Figura 4 - gráfico

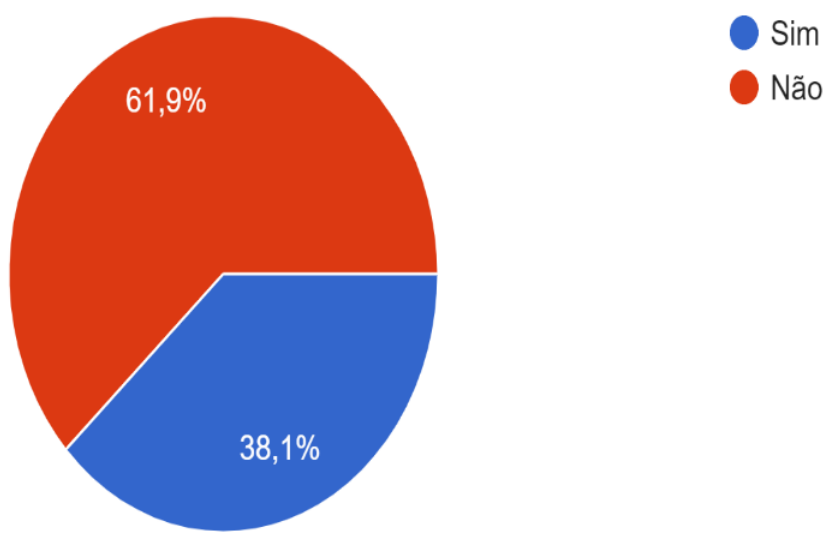

Fonte: Autores (2020).

- Se sim, quanto paga?

Figura 5 - gráfico

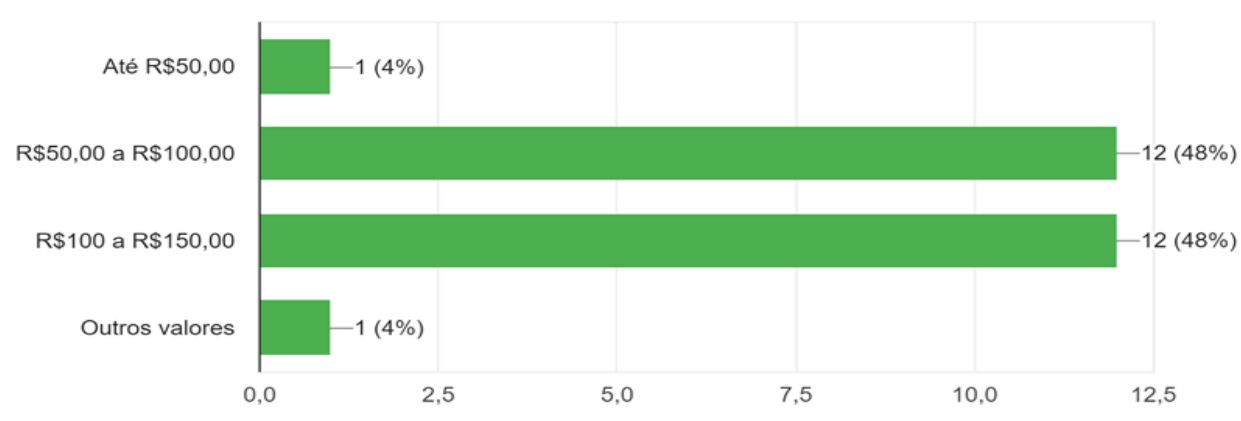

Fonte: Autores (2020).

- Se não, por qual motivo?

Figura 6 - gráfico
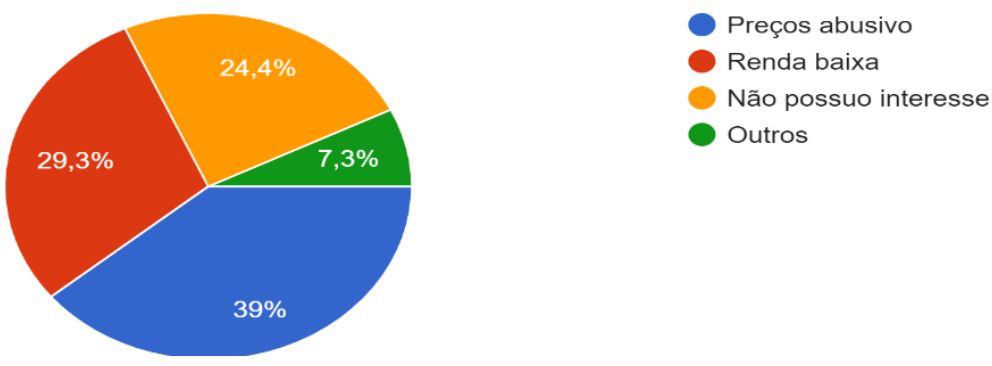

Fonte: Autores (2020). 
- Você escolheria assinar pacotes onde pudesse escolher o catálogo de canais? Ou prédefinidos?

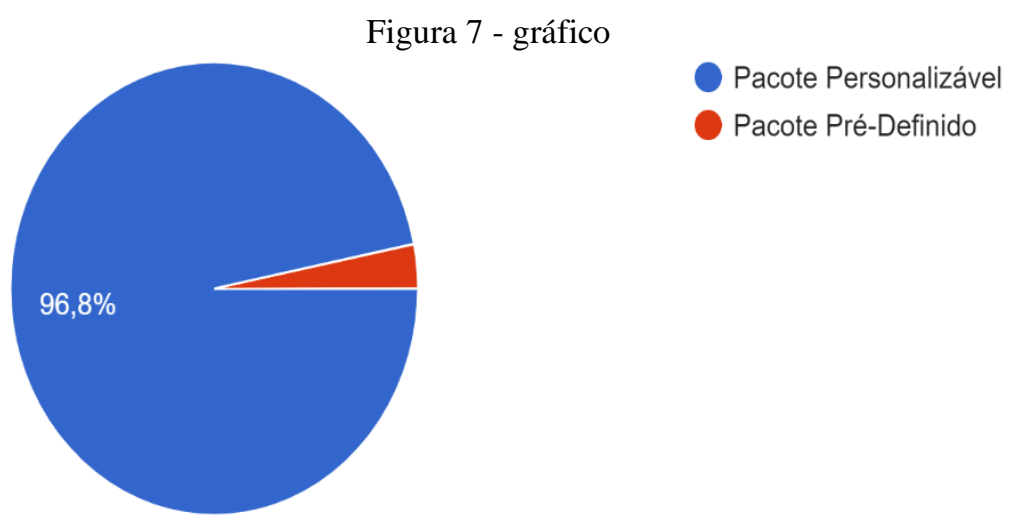

Fonte: Autores (2020).

- Você assinaria algum plano se houvesse a opção de escolha de canais ao seu gosto? (Diminuindo ou aumentando a opção de canais em proporção ao preço sugerido)

Figura 8 - gráfico

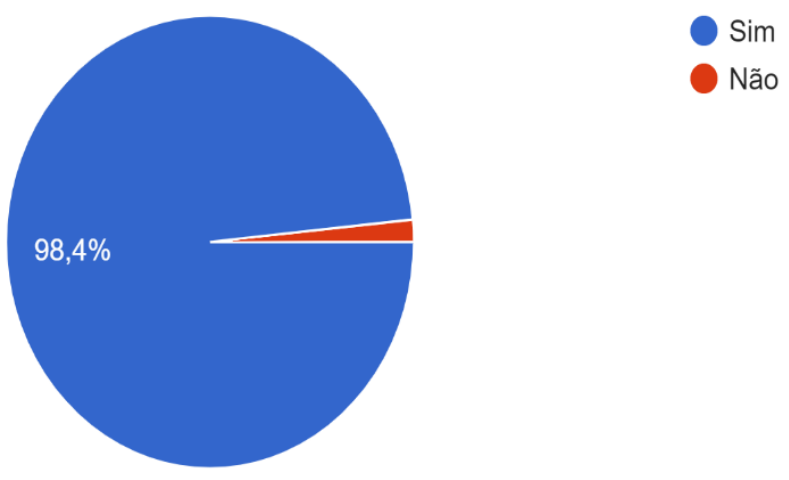

Fonte: Autores (2020). 
- O que você busca ao assinar uma TV a cabo?

Figura 9 - gráfico

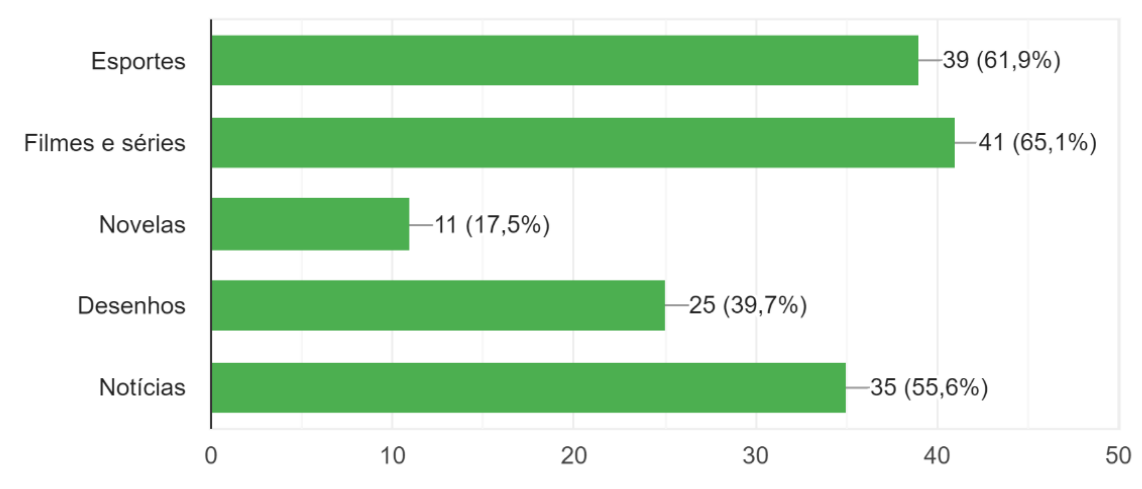

Fonte: Autores (2020).

\section{Aplicação das ferramentas da qualidade}

No diagrama de Ishikawa se foi escolhido a perda de assinantes como problemática central a ser analisada.

Figura 10 - Aplicação de Ishikawa

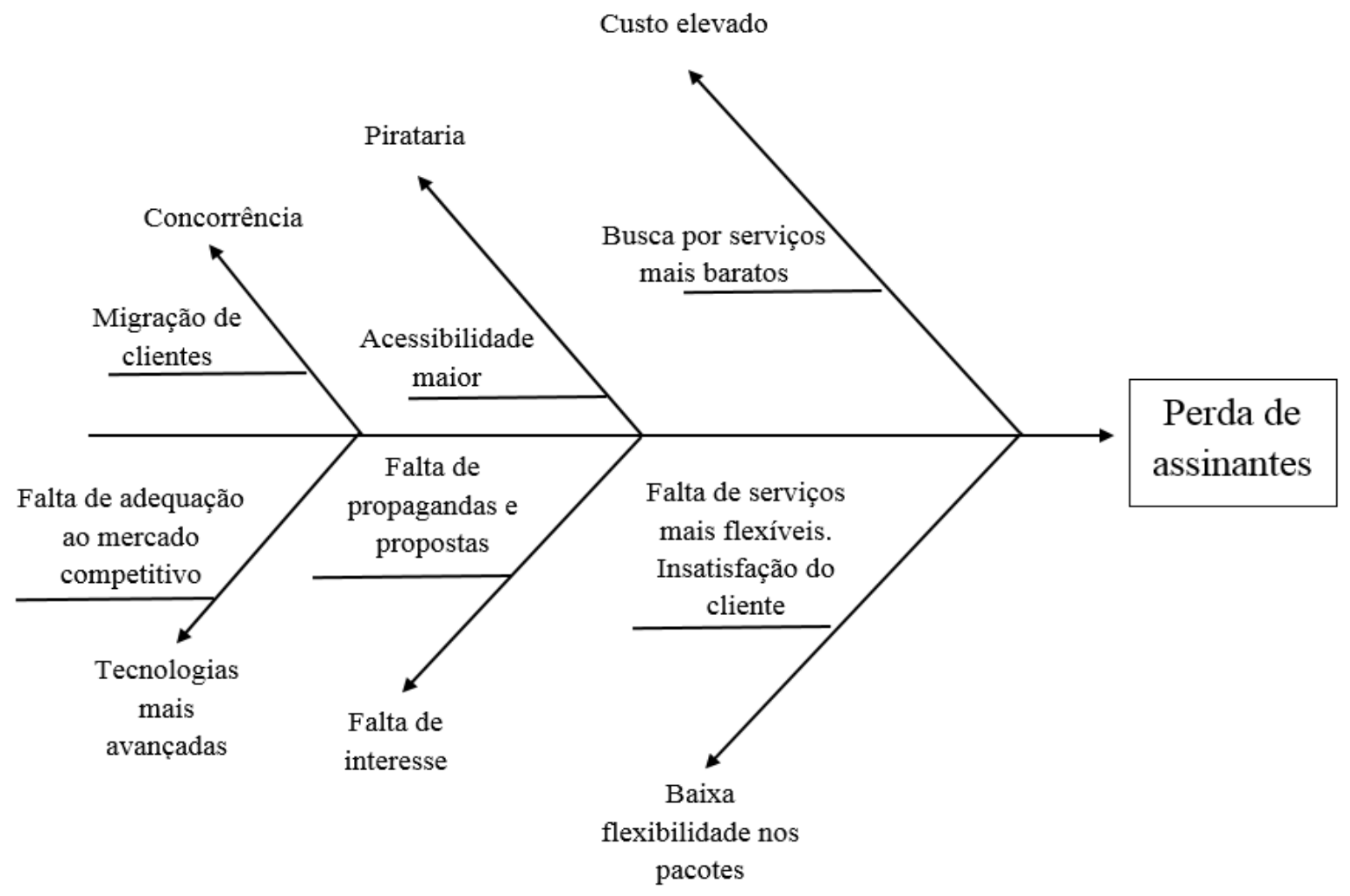

Fonte: Autores (2020). 
Podemos visualizar mais claramente as raízes presentes na problemática que vem ocasionando a redução contínua de assinantes dos sistemas de TV a cabo, o que tem causado transtornos as empresas que atuam na área.

Na matriz GUT aplicaremos três dos itens elencados no diagrama de Ishikawa, os escolhidos foram a busca por serviços mais baratos, falta de adequação ao mercado competitivo e a baixa flexibilidade nos pacotes, estes foram identificados como mais ocorrentes e mais definitivos para a perda de clientes.

Tabela 2 - Aplicação da matriz GUT

\begin{tabular}{|l|c|c|c|c|}
\hline Problema & Nota & Gravidade & Urgência & tendência \\
\hline $\begin{array}{l}\text { busca por serviços mais } \\
\text { baratos }\end{array}$ & 125 & 5 & 5 & 5 \\
\hline $\begin{array}{l}\text { falta de adequação ao } \\
\text { mercado competitivo }\end{array}$ & 125 & 5 & 5 & 5 \\
\hline $\begin{array}{l}\text { baixa flexibilidade nos } \\
\text { pacotes }\end{array}$ & 100 & 5 & 5 & 4 \\
\hline
\end{tabular}

Fonte: Autores (2020).

$\mathrm{Na}$ matriz GUT podemos visualizar as problemáticas que devem ser priorizadas em relação as falhas identificadas na forma em que as operadoras do sistema de TV a cabo utilizam atualmente, podendo investir em novas formas de manter o cliente em seu serviço, como flexibilização nos pacotes ofertados.

\section{Conclusão}

Mais pessoas estão procurando por meios que se adequem as suas preferências como os serviços de streaming que se equipara a TV por assinatura, onde estes atuam proporcionando uma maior flexibilidade seja de horários como de acesso ao conteúdo que o assinante queira assistir na hora que ele desejar ao contrário dos canais convencionais que possuem horário fixo para exibição de seus programas. 
O contexto atual da sociedade dinâmica em que vivemos não nos permiti ter tanta disponibilidade de horários, tendo em vista que muitos dos canais ofertados pelos planos prédefinidos da TV por assinatura não se enquadram nas preferências dos usuários que devido ao esse tipo de pacote estarão pagando mais por canais que não serão aproveitados.

Diante da situação apresentada propomos que o serviço de TV por assinatura construa uma plataforma mais flexível para o usuário, permitindo com que tal tenha a opção de personalizar o seu próprio pacote de acordo com suas preferências, seja optando por canais de filmes, séries, notícias, esportes, desenhos entre outros, que proporcionará uma melhor experiência mais dinâmica para o usufruidor, também podendo atribuir as organizações do ramo aumento no número de adesões aos seus serviços, assim crescendo no mercado competitivo e se diferenciando de seus demais concorrentes .

\section{Referencias}

BEHR, Ariel; MORO, Eliane Lourdes da Silva; ESTABEL, Lizandra Brasil. Gestão da biblioteca escolar: metodologias, enfoques e aplicação de ferramentas de gestão e serviços de biblioteca. Ciência da informação. Brasília. Vol. 37, n. 2 (maio/ago. 2008), p. 32-42, 2008.

BETTI, Mauro. Esporte, televisão e espetáculo: o caso da TV a cabo. Conexões: Educação Física, Esporte e Saúde, v. 1, n. 3, p. 74-91, 1999.

Bezerra, Isamara de Melo Dantas; Tinoco, Dellano Jatobá Bezerra. Aplicação das ferramentas da qualidade em projetos governamentais - um estudo de caso do projeto de integração das bacias do Rio São Francisco. ENEGEP 2019. Santos, SP. Disponível em: <http://www.abepro.org.br/biblioteca/TN_STO_000_1658_38046.pdf>. Acessado em: 25 de novembro, 2019.

Bioma Amazônico. Disponível em: <https://www.ibflorestas.org.br/bioma-amazonico>. Acessado em: 05 de julho 2019.

BRITTOS, Valério Cruz. TV a cabo: a dispersão da audiência. Universidade do Vale do Rio dos Sinos (UNISINOS), http://bocc. ubi. pt/pag/brittos-valerio-televisão-cabodispersao. html, 2016.

Evolução do Número de Assinantes de TV por Assinatura. Disponível em: <http://www.abta.org.br/>. Acessado em: 25 de novembro de 2019. 
Qual proporção da população tem televisão por assinatura. Disponível em: < https://www.nexojornal.com.br/grafico/2019/06/18/Qual-propor\%C3\%A7\%C3\%A3o-dapopula\%C3\%A7\%C3\%A3o-tem-televis\%C3\%A3o-por-assinatura; >. Acessado em: $29 / 11 / 2019$

TV por assinatura perde 550 mil clientes em 2018. Disponível em: < https://www.anatel.gov.br/institucional/noticias-destaque/2187-tv-por-assinatura-perde-550mil-assinantes-em-2018>. Acessado em: 29/11/19

VICENTE, Eduardo; KISCHINHEVSKY, Marcelo; MARCHI, Leonardo de. A consolidação dos serviços de streaming: reconfiguração dos mercados de mídia sonora e desafios à diversidade musical no Brasil. Anais, 2016. 